\title{
Outbreak
}

\section{Norovirus outbreak among students of a boarding school in Kluang, Johor, Malaysia}

\author{
Mohamad Nizam Subahir ${ }^{1}$, Mohammad Saffree Jeffree², MohdRohaizat Hassan ${ }^{3}$, MdFaizulAbd Razak ${ }^{1}$, \\ Syarifah Noor Ghulam Mohamad ${ }^{1}$, Siat Yee Fong ${ }^{4,5}$, Kamruddin Ahmed ${ }^{5,6}$ \\ ${ }^{1}$ Kluang District Health Office, Kluang, Johor, Malaysia \\ ${ }^{2}$ Department of Community and Family Medicine, Faculty of Medicine and Health Sciences, Universiti Malaysia \\ Sabah, Kota Kinabalu, Sabah, Malaysia \\ ${ }^{3}$ Department of Community Health, Faculty of Medicine, UKM Medical Centre, Cheras, Kuala Lumpur, Malaysia \\ ${ }^{4}$ Department of Biomedical Sciences and Therapeutics, Faculty of Medicine and Health Sciences, Universiti \\ Malaysia Sabah, Kota Kinabalu, Sabah, Malaysia \\ ${ }^{5}$ Borneo Medical and Health Research Centre, Faculty of Medicine and Health Sciences, Universiti Malaysia \\ Sabah, Kota Kinabalu, Sabah, Malaysia \\ ${ }^{6}$ Department of Pathobiology and Medical Diagnostics, Faculty of Medicine and Health Sciences, Universiti \\ Malaysia Sabah, Kota Kinabalu, Sabah, Malaysia
}

\begin{abstract}
Introduction: Norovirus (NoV) is a contagious virus causing acute gastroenteritis and is mainly responsible for diarrheal outbreak in closed settings. The aims of this study were to describe the epidemiological characteristic of an outbreak in a boarding school, to assess the extent of the outbreak and to implement appropriate control measures.

Methodology: A descriptive study was conducted to describe the epidemiological characteristics of the outbreak. Data on demographic details, onset of abdominal symptoms, food intake history and contact with ill person three days prior to illness were obtained.

Results: Twelve fresh stool and 14 food samples were tested for NoV and enteric pathogens, respectively. Out of 745 students, 42 (5.6\%) were infected during this outbreak. Predominant clinical features were diarrhea (76.1\%), vomiting (71.4\%) and abdominal pain (67\%). Eight (67\%) stool samples and six (43.9\%)food samples were positive for NoV and total coliforms, respectively. The dissemination of the disease was due to poor hygiene practices among students. Quarantine was imposed until the last case on September 28, 2016. The outbreak was declared over on September 30, 2016.

Conclusions: A NoV outbreak was determined first time in Malaysia. Environmental assessment showed poor hygienic conditions in the school's kitchen. The number of infected students increased considerably despite the implementation of preventive and control measures. Quarantine was effective to stop the outbreak which is characteristics of NoV outbreak.
\end{abstract}

Key words: norovirus; outbreak; boarding school; children; Malaysia.

J Infect Dev Ctries 2019; 13(4):274-277. doi:10.3855/jidc.11199

(Received 02 January 2019 - Accepted 26 February 2019)

Copyright (C) 2019 Subahir et al. This is an open-access article distributed under the Creative Commons Attribution License, which permits unrestricted use, distribution, and reproduction in any medium, provided the original work is properly cited.

\section{Introduction}

Globally, acute gastroenteritis remains a significant burden of the health care system $[1,2]$. Across all age groups, norovirus (NoV) is the most common cause of the 685 million diarrheal episodes and 212,000 deaths $[3,4]$. NoV is the major cause of community acquired diarrhea among children in developing countries [5]. It is highly infectious and transmitted primarily from person-to-person within closed settings such as schools, cruise ships, hospitals, child care facilities and institutions for elderly [6,7]. It can also spread through contaminated food and drinks, as well as via aerosol formation $[8,9]$. There is a lack of published reports on
NoV from Malaysia. This is the first outbreak we encountered in Kluang district of Johor state and we analyzed the epidemiological characteristics which can be useful for the evaluation of future outbreak and thus prevention.

\section{Methodology}

On September 24, 2016, the Kluang District Health Office received notification of food poisoning from Enche' Besar Hajah Khalsom Hospital involving seven students from a boarding school. A team was sent immediately to investigate and confirm the outbreak, to 
identify the risk factors, and to come out with recommendations to control the outbreak.

Case findings: active case findings and passive case findings

A case was defined as a student from the school who had acute gastroenteritis symptoms, including vomiting, diarrhea, abdominal pain, nausea and fever from September 18 to 22, 2016.

Active case detection was done for all students and staff of the school. Those fulfilled the case definition were interviewed and examined. Demographic details, onset of symptoms, history of food intake and information on any contact with ill persons was obtained. Cases who presented with dehydration was referred to the nearest health center.

\section{Laboratory investigation}

A total of 12 fresh stool samples were collected from the students who fulfilled the case definition and samples were sent to the National Public Health Laboratory, Sungai Buloh to test for NoV and rotavirus using a commercially available kit (RidaQuick Norovirus, R-Biopharma AG, Darmstadt, Germany and SD Bioline Rotavirus, Standard Diagnostics Inc., Gyeonggi-do, Republic of Korea). In addition, eight rectal swabs from the cases, six rectal swabs from food handlers, six environmental swabs and 14 food samples (proxy sample) were taken and sent to the Public Health Laboratory in Johor Bahru to test for enteric bacteria.

\section{Environment investigation}

Food safety and risk assessment was done at both the school's canteen and the kitchen using a standard form provided by the Ministry of Health Malaysia. Besides, environmental assessment was done in the students' hostel, academic blocks and the school's environment to assess hygienic practices and other risk factors that might contribute to the dissemination of diarrhea.

Analytical study

Data were analyzed using SPSS version 19.0 and Epi Info 7.2.

\section{Results}

In September 2016, a NoV outbreak occurred in a boarding school located about 12 kilometers from Kluang town, which involved 745 students, where 350 of them were male and 395 were female. The students had limited exposure to outside environments except some of them were visited by family members during the weekend.

\section{Descriptive study}

A total of 42 students fulfilled the case definition of the outbreak in which the male:female ratio was 4.25:1. The attack rate was $5.6 \%$, while it was higher for male students $(9.7 \%)$ compared to females $(2.0 \%)$ (Table 1$)$. There were no cases among teachers and other staff. The age distribution of the cases was in the following order: eight (19.0\%) were 13 years old, seven (16.7\%) were 14 years old, $14(33.3 \%)$ were 15 years old, five (11.9\%) were 16 years old, and eight (19.0\%) were 17 years old.

Of the 42 students, $26(61.9 \%)$ were referred to the nearest health center for further treatment. None of them required admission and were provided outpatient treatment, indicating that their conditions were not severe. The symptoms of gastroenteritis were diarrhea $(32,76.1 \%)$, vomiting $(30,71.4 \%)$, abdominal pain $(28$,

Figure 1. The epidemic curve of norovirus outbreak at the boarding school in Kluang, Johor, Malaysia during September 2016. The numbers of cases were plotted against the day of occurrence of diarrhea.

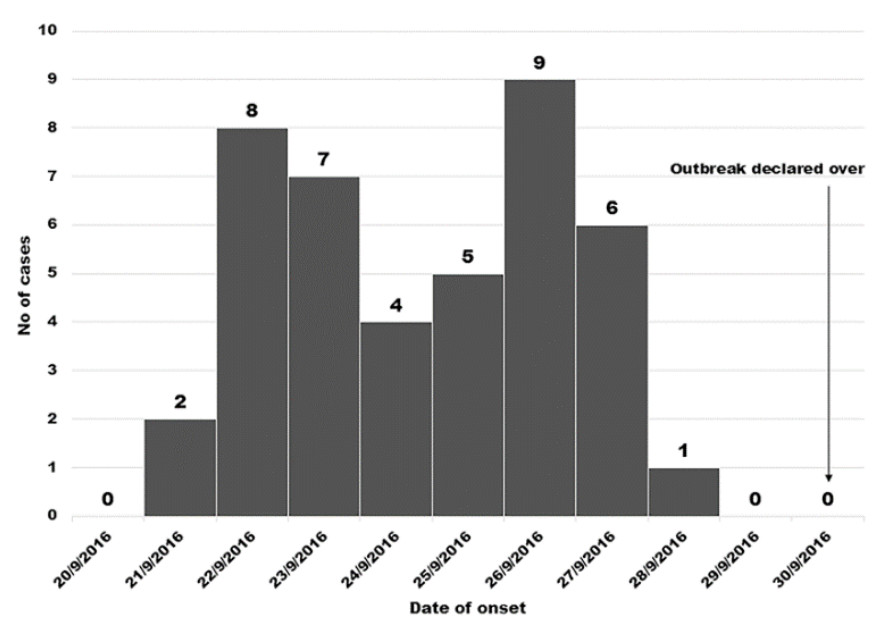

Table 1. The gender specific distribution of students infected with diarrhea during the outbreak.

\begin{tabular}{cccc}
\hline Gender & Number of student (a) & Number of infected students (b) & $\begin{array}{c}\text { Percentage } \\
\text { b/a } \times \mathbf{1 0 0}\end{array}$ \\
Male & 350 & 34 & 9.71 \\
Female & 395 & 8 & 2.03 \\
Total & $\mathbf{7 4 5}$ & $\mathbf{4 2}$ & $\mathbf{5 . 6 4}$ \\
\hline
\end{tabular}


$67 \%)$, nausea $(14,40.0 \%)$, headache $(14,40.0 \%)$, and fever $(4,9.5 \%)$.

The epidemic curve (Figure 1) shows that this was a propagated source outbreak and transmitted through person-to-person contact. The onset was reported on September 21, 2016 and the last cases were reported on September 28, 2016. There were two peaks in the curve, one on September 22 and the other one on September 26, 2016. The second peak was higher than the first peak, representing a rapid outbreak dissemination following the first peak.

\section{Laboratory investigations of stool}

Eight $(66.7 \%)$ of the twelve stool samples were positive for NoV. None of the samples were positive for rotavirus. No pathogenic bacteria were detected in the rectal swabs from the cases and food handlers.

All food samples were negative for Escherichia coli, Salmonella spp, Bacillus cereus, and Vibrio cholerae. However, the environmental samples were positive for total coliform and a sample was also positive for coagulase positive Staphylococci.

\section{Discussion}

Upon notification of the first case on September 24, 2016, at $11.15 \mathrm{pm}$, we conducted field investigation in the next morning and found 21 students with acute gastroenteritis. In this school, meals were prepared in the dormitory kitchen and served in the dining hall. The hygienic condition of the dormitory kitchen was not satisfactory. Students were allowed to buy food from the school's canteen and also parents or guardians were allowed to bring in any food and students were also permitted to bring food from home after holidays.

Although only 12 samples were available for NoV testing and eight of them were positive, we could not apply the Kaplan criteria [10] to determine that the outbreak was caused by NoV. Although more than 50\% of the cases had vomiting and no pathogenic bacterial growth was observed in submitted samples, therefore, applying other criteria were challenging. The outbreak continued for eight days, indicating that even though the outbreak initially started by consumption of contaminated food, the subsequent spread was from person-to-person which is supported by the epidemic curve. One of the weaknesses of the study was that genotyping of NoV could not be performed. Genotype data could be used to compare strains with an outbreak in other countries or could be used for future outbreaks in Malaysia.

This study is in agreement with other studies [1115], showing that NoV spreads rapidly among students with close proximity to one another and who share common places for activities. Furthermore, notification was delayed, which was made four days after the onset of the first case. Within that period, the infection has already spread to 21 students. Therefore, all cases were isolated in a sick room and specific dorm. All school buildings were disinfected with benzalkonium chloride and chloroxylenol. Health education training were provided to all students and staff, including food handlers and cleaners, especially on proper hand washing and cleanliness of toilets and bathroom. Even after implementing the preventative and control measures, within the next three days, the number of infected students increased to 42 . Therefore, quarantine was imposed until the last onset of the case on September 28, 2016and finally, the outbreak was declared over on September 30, 2016.

NoV cases or outbreaks have never been reported in Malaysia. As a result, diagnostic facilities for $\mathrm{NoV}$ infection were not readily available; hence, NoV was not considered as the cause of the present outbreak initially. Underreporting might be one of the reasons for the lack of publications on NoV in Malaysia. Further studies are needed to understand the burden of NoV in the country.

\section{Conclusion}

A diarrheal outbreak by NoV was identified in a boarding school in Malaysia. Possibly the virus was initially transmitted by food and then person-to-person transmission occurred. All food samples were negative for other bacteria causing diarrhea. The outbreak was so severe that all measures were ineffective to control the outbreak requiring implementation of quarantine. Traditionally diarrheal outbreak by NoV is not considered in Malaysia. Therefore, samples were submitted for identification of bacteria and were negative for any growth. This caused a delay in identifying the causative agent of this outbreak. This study might encourage looking for viral etiology in future diarrheal disease outbreak investigations.

\section{Acknowledgements}

We thank the Director General of Health Malaysia for permission to publish this paper. We also thank all staff of Kluang District Health Office and staff of the boarding school.

\section{References}

1. Liu L, Johnson HL, Cousens S, Perin J, Scott S, Lawn JE, Rudan I, Campbell H, Cibulskis R, Li M, Mathers C, Black RE (2012) Global, regional, and national causes of child mortality: 
an updated systematic analysis for 2010 with time trends since 2000. Lancet 379: 2151-2161.

2. Walker CLF, Rudan I, Liu L, Nair H, Theodoratou E, Bhutta ZA, O'Brien KL, Campbell H, Black RE (2013) Global burden of childhood pneumonia and diarrhoea. Lancet 381: 14051416.

3. Ahmed SM, Hall AJ, Robinson AE, Verhoef L, Premkumar P, Parashar UD, Koopmans M, Lopman BA (2014) Global prevalence of norovirus in cases of gastroenteritis: a systematic review and meta-analysis. Lancet Infect Dis 14:725-730.

4. Pires SM, Fischer-Walker CL, Lanata CF, Devleesschauwer B, Hall AJ, Kirk MD, Duarte ASR, Black RE, Angulo FJ (2015) Aetiology-specific estimates of the global and regional incidence and mortality of diarrhoeal diseases commonly transmitted through food. PLoS One10: e0142927.

5. Platts-Mills JA, Babji S, Bodhidatta L, Gratz J, Haque R, Havt A, McCormick BJ, McGrath M, Olortegui MP, Samie A, Shakoor S, Mondal D, Lima IF, Hariraju D, Rayamajhi BB, Qureshi S, Kabir F, Yori PP, Mufamadi B, Amour C, Carreon JD, Richard SA, Lang D, Bessong P, Mduma E, Ahmed T, Lima AA, Mason CJ, Zaidi AK, Bhutta ZA, Kosek M, Guerrant RL, Gottlieb M, Miller M, Kang G, Houpt ER (2015) Pathogen-specific burdens of community diarrhoea in developing countries: a multisite birth cohort study (MALED). Lancet Glob Health3: e564-575.

6. Adler JL, Zick1 R (1969) Winter vomiting disease. J Infect Dis 119:668-673.

7. White PA (2014) Evolution of norovirus. Clin Microbiol Infect 20:741-745.

8. Patel MM, Hall AJ, Vinjé J, Parashar UD (2009) Noroviruses: a comprehensive review. J ClinVirol44:1-8.

9. Marks PJ, Vipond IB, Carlisle D, Deakin D, Fey RE, Caul EO (2000) Evidence for airborne transmission of Norwalk-like virus (NLV) in a hotel restaurant. Epidemiol Infect 124:481487.

10. Kaplan JE, Feldman R, Campbell DS, Lookabaugh C, Gary GW (1982) The frequency of a Norwalk-like pattern of illness in outbreaks of acute gastroenteritis. Am J Public Health72: 1329-1332.

11. Centers for Disease Control and Prevention (2018) Trends and Outbreaks. Available: https://www.cdc.gov/norovirus/trendsoutbreaks.html.Accessed 10 April 2019.

12. Menezes FG, Correa VMSP, Franco FGM, Ribeiro MI, Cardoso MFS, Morillo SG, Carmona RCC, Timenetsky MCST, Correa L, Pasternak J (2010) An outbreak of norovirus infection in a long-term care facility in Brazil. Einstien 8: 410413.

13. Le Blanc JJ, Petipass J, Gaston D, Taylor R, Hatchette TF, Booth TF, Mandes R, McDermid A, Grudeski E (2016) Outbreak of norovirus GII.P17 - GII.17 in the Canadian Province of Nova Scotia. Can J Infect Dis Med Microbiol 2016:1-6.

14. Gupta S, Singh KP, Jain A, Srivastava S, Kumar V, Singh M (2015) Aetiology of childhood viral gastroenteritis in Lucknow, north India. Indian J Med Res 141:469-472.

15. Aragao GC, Mascarenhas JDP, Kaiano JHL, de Lucena MSS, Siqueira JAM, Fumian TM, Hernandez JDM, de Oliveira CS, Oliveira DDS, Araujo EDC, Soares LDS, Linhares AC, Gabbay YB (2013) Norovirus diversity in diarrheic children from an African-descendant settlement in Belem, Northern Brazil. PLoS One. 8: e56608.

\section{Corresponding author}

Prof. Dr. Kamruddin Ahmed

Borneo Medical and Health Research Centre, Faculty of Medicine and Health Sciences, Universiti Malaysia Sabah, Jalan UMS, 88400 Kota Kinabalu, Sabah, Malaysia.

Tel: +60-88-320-000 ext. 611481, Fax: +60-88-321-373,

Email: ahmed@ums.edu.my

Conflict of interests: No conflict of interests is declared. 